\title{
O JOGO DE AREIA COMO FERRAMENTA NA EDUCAÇÃO AMBIENTAL
}

\author{
Maria das Dôres Farias Rodrigues ${ }^{1}$ \\ Karla Rosane do Amaral Demoly ${ }^{2}$
}

Resumo: Este artigo discute experiências de formação em educação ambiental desenvolvidas no emprego do artefato técnico designado como jogo de areia em uma escola pública estadual de Mossoró-RN. A rede teórica de sustentação da análise encontramos desde a invenção da ferramenta jogo de areia com os trabalhos de Dora Kalff, Margareth Lowenfeldt, dentre outros que trazem o enfoque da Psicologia Clínica. Temos a relação ainda recente do jogo de areia na educação escolar e nosso estudo participa desta construção embasada nas teorias da Biologia da Cognição de Humberto Maturana em diálogo com outros pesquisadores. A vivência que o jogo de areia oportuniza para estudantes indicam que esta tecnologia favorece o conhecimento nos processos que configuram o aprender a cuidar de si e do meio ambiente também a partir da escola.

Palavras-chave: jogo de areia, tecnologia, educação ambiental, transformação.

\footnotetext{
${ }^{1}$ Universidade Federal Rural do Semi-Árido. E-mail: mariadasdoresrodrigues@uol.com.br ${ }^{2}$ Universidade Federal Rural do Semi-Árido. E-mail: karla.demoly@ufersa.edu.br 


\section{Introdução}

A presença do jogo no processo de conhecimento é destacada por alguns brilhantes cientistas que se dedicam na análise de processos humanos de aprendizagem. Podemos indicar alguns pesquisadores que exerceram influências importantes no modo como consideramos o jogo e a aprendizagem. Donald Woods Winnicott (1973) considera a criança em processo contínuo de constituir-se sujeito em um corpo que se desenvolve, amadurece e cresce em interação permanente com 0 ambiente. A teoria do objeto transicional de Winicott discute o brincar e a criança enquanto sujeito que se apropria de experiências com e através de um espaço situado entre o real e a fantasia. Já o historiador P. Ariès (1978) nos apresenta no livro História social da criança e da família, a sociedade primitiva em que o jogo não aparecia como discriminação e preconceito na convivência na hora dos jogos e brincadeiras entre as crianças e adultos. A liberdade e falta de regras rígidas no jogo era característica de uma dinâmica natural e cultural na época.

Johan Huizinga (1938), no prefácio do livro Homo Ludens, apresenta o jogo como elemento da cultura, descrevendo as designações atribuídas ao ser humano em sua relação com o jogo. Para o autor, "é no jogo e pelo jogo que a civilização surge e se desenvolve (...)" (HUIZINGA, 1938, Parte. I). O conceito de Homo Ludens enfatiza o homem que se diverte. O próprio ato de jogar transparece e é considerado fundamental no processo de desenvolvimento humano. No percurso histórico dos séculos XVII e XVIII, os jogos adotaram outras conceituações diferentes da sua origem na sociedade primitiva. Uma preocupação mais acentuada com a moral e a educação traz como efeito uma ação de proibir determinados jogos, estes considerados maus, e todo um direcionamento para aqueles que eram julgados como bons, segundo os padrões morais da época.

A palavra jogo sofre muitas modificações até chegarmos a um entendimento comum de que é a atividade essencial na construção do ser humano desde a infância. $O$ ato de jogar apresenta significados e o que nos interessa é trazer para nosso estudo as produções que consideram o jogo como artefato potencializador de conhecimento na educação.

\section{O jogo de areia na interface psicologia-educação}

O jogo passa a ser estudado em perspectiva científica nas áreas psicológica, psicanalítica e pedagógica no final do século XIX, dando início a várias teorias e concepções quando se pretende explicar e analisar as contribuições do jogo na vida humana. Ressaltamos aqui a teoria de recapitulação de Stanley Hall (1906) em que, "o jogo é visto como forma de recapitular gerações passadas, caracterizando a função atávica da atividade lúdica" (SANTOS, 2008, p.17). Ao longo da história, é definido ainda como parte do desenvolvimento biológico, na luta e habilidade para competir nos eventos esportivo, social e educativo. 
Entendemos o jogo como uma das atividades que mais proporciona bem estar à vida humana, pois favorece a imaginação e a inventividade que são cruciais no percurso de aprendizagem. Processos de conhecimento envolvem o fazer e este, em sua complexidade, integra dimensões da vida humana. Ao observarmos atos de conhecimento nos deparamos com inscrições, sentimentos, ideias, sonhos, curiosidades, dores, enfim, percursos de conhecimento e aprendizagem, busca de manutenção da vida e mudança estrutural contínua (MATURANA, 2001) . O jogo que, em psicologia participa de processos de tratamento, assume em pedagogia uma função lúdica e didática quando desenvolvemos projetos de educação ambiental.

Ao referirmos o "jogo de areia" temos expressões divulgadas quanto ao termo em seu procedimento. $\mathrm{O}$ jogo de areia emerge como técnica terapêutica relacionada aos conceitos da Psicologia Analítica de C. G. Jung, de onde destacamos alguns elementos iniciais.

\begin{abstract}
A Psicologia Junguiana permite que se adote uma abordagem qualitativa de pesquisa em que fenômenos ou fatos clínicos sejam descritos. Esta abordagem, por sua vez, permite que se discutam aspectos subjetivos da atividade clínica que tendem a se repetir e diferentes processos, preservando singularidades e idiossincrasia. Seu maior mérito está na contribuição que pode oferecer à construção do conhecimento da singularidade humana, permitindo que se aplique 0 critério de transferibilidade dos resultados. (FRANCO; PINTO, 2003, p.100-101)
\end{abstract}

Ao considerarmos esta rede teórica de sustentação da invenção técnica, fazemos um deslocamento para propor o jogo de areia como um artefato em suas possibilidades no campo da educação. A experiência em educação ambiental situa 0 jogo de areia enquanto tecnologia, dispositivo capaz de potencializar modos de conhecer-viver. A ferramenta do jogo de areia se integra a um conjunto de dispositivos, artefatos técnicos que favorecem o desenvolvimento de metodologias pertinentes ao trabalho educativo, mais diretamente, ao campo da educação ambiental, onde processos cognitivos e subjetivos acontecem de modo inseparável na experiência humana.

Existem duas abordagens que vale referir de estudiosos que apontam diferenças sobre o modo como utilizamos 0 jogo de areia em educação. A primeira é europeia e aponta que o jogo de areia deve ser aplicado como quando foi criado por Dora Kalf, ao introduzir o jogo nos processos psicoterápicos e psicodiagnósticos. A autora desenvolveu experiências com o jogo em 1957, enquanto que Margareth Lowenfeld, psicanalista inglesa, utilizava bandejas de zinco e areia no tratamento de seus pacientes. Dora Kalf cria seu procedimento associado aos conceitos e elementos da técnica à teoria de Jung, conforme já referimos antes, ao perceber que seus pacientes construíam cenários com miniaturas dentro de uma caixa com areia. A

revista brasileira educação ambiental 
psicanalista considera que estes cenários expressam conceitos ainda inconscientes em linguagem pré-verbal. Neste sentido, ao estimular o sujeito à regressão criativa, desenvolve processo terapêutico como uma aposta na capacidade de auto - cura do self. Já Margareth Lowenfeld, norte-americana, faz a distinção no modo de aplicação do jogo de areia, ampliando o setting e a forma de interpretá-lo. O Setting é o lugar onde acontecem as transformações. É considerado essencial e precisa estar sempre organizado e preparado para receber o sujeito com as miniaturas disponíveis em prateleiras, as caixas de areia limpas e água também disponíveis em reservatórios pequenos.

O jogo de areia foi utilizado com crianças na Inglaterra em 1935 com a pesquisa e o trabalho da psiquiatra Margaret Lowenfeld, portanto: "(...) desde os seus primórdios, o jogo de areia já se caracterizava como meio através do qual a vida emocional e mental das crianças era comunicada numa forma que poderia ser objetivamente registrada e analisada" (FRANCO; PINTO, 2003, p.104).

Quanto ao elemento areia e seu processo de interação com o homem, vale ressaltar que integra a experiência desde a antiguidade. Segundo Weinrib (1993 apud CAVALCANTE, 2012), as tribos primitivas usavam a areia como substrato para desenhar círculos mágicos em cerimônias de curas, adivinhações e outras. Para os autores, estes são os primeiros usuários do jogo de areia. Ao desenhar os círculos mágicos, eles estavam definindo os territórios onde o fluxo energético era capaz de promover a cura, ou seja, territorializando com desenhos o espaço de processamento das curas. (WEINRIB apud CAVALCANTE, 2010, p.131).

Encontramos no conhecimento do senso comum e em relatos de algumas pessoas o modo como se percebem afetadas no contato com a areia, resistência ao contato com areia ou com o que sente o corpo ao pisar no chão, seja na praia ou em outros lugares. Experiências demonstram a resistênica ou o prazer de sentir e a potencialidade da sensação de bem estar no contato do corpo com a areia, a alegria e leveza neste fazer. As reações possíveis estão relacionadas a situações que se referem à experiência, processos cognitivossubjetivos que tecem a vida humana. "(...) não se pode ensinar utilizando-se somente o pensamento, a sensação e a extroversão sem deixar de lado uma imensa parte do potencial psíquico no aprendizado" (BYINGTON, 1993, p.17).

Fritjof Capra é um pesquisador dos campos da física e da filosofia que produz com outros cientistas uma perspectiva de conhecimento que aponta para necessidade de mudanças no modo de considerarmos a vida. O autor, ao indicar a perspectiva sistêmica em que para compreender um fenômeno precisamos olhar dando voltas, fazendo conectar processos que estavam disjuntos na perspectiva cartesiana, refere também à sua experiência pessoal com a areia. No prefácio do livro: "O Tao da Física", Capra traz seu envolvimento com a areia e sua alegria e prazer em desfrutá-la, bem como, o sentimento íntimo na defesa de uma ecologia profunda no modo de compreensão da vida humana no Planeta Terra. Nas palavras do autor: 
Em 1969 experimentei algo de muito belo, que me levou a percorrer o caminho que acabaria por resultar neste livro (referindo-se ao livro Tao da Física). Eu estava sentado na praia, ao cair de uma tarde de verão, e observava o movimento das ondas, sentindo ao mesmo tempo o ritmo de minha própria respiração. Nesse momento, subitamente, apercebi-me intensamente do ambiente que me cercava: este se me afigurava como se participasse de uma gigantesca dança cósmica. Como físico, eu sabia que a areia, as rochas, a água e o ar a meu redor eram feitos de moléculas e átomos em vibração que tais moléculas e átomos, por seu turno, consistiam em partículas que interagiam entre si através da criação e da destruição de outras partículas. Sabia, igualmente, que a atmosfera da Terra era permanentemente bombardeada por chuvas de raios cósmicos, partículas de alta energia e que sofriam múltiplas colisões à medida que penetravam na atmosfera. Tudo isso me era familiar em razão de minha pesquisa em Física de alta energia; até aquele momento, porém, tudo isso me chegara apenas através de gráficos, diagramas e teorias matemáticas. Sentado na praia, senti que minhas experiências anteriores adquiriam vida. Assim, "vi" cascatas de energia cósmica, provenientes do espaço exterior, cascatas nas quais, em pulsações rítmicas, partículas eram criadas e destruídas. "Vi" os átomos dos elementos

- bem como aqueles pertencentes a meu próprio corpo participarem desta dança cósmica de energia. Senti o seu ritmo e "ouvi" o seu som. Nesse momento compreendi que se tratava da Dança de Shiva, o Deus dos Dançarinos, adorado pelos hindus (CAPRA, 1989, p. 09).

Capra sente ao tocar na areia, sentado na praia, o espaço de conexão com o ambiente em que uma sinergia se produz, ao sentir e se perceber como parte de um universo maior, como parte de uma dança cósmica. Vale ressaltar que Shiva não é apenas o Deus dos dançarinos, mas o destruidor e criador ao mesmo tempo. Shiva destrói o velho que já não tem utilidade para dar lugar à invenção do novo, simboliza a passagem das estações, os ciclos da vida de nascimento, vida e morte, o eterno movimento da transformação. Shiva, muito mais que o Deus da dança, é o Deus transformador, como os processos de invenção permanente da vida e do conhecimento. Seu movimento ininterrupto e ritmado é a dança transformadora que manter o todo em equilíbrio.

Nessa trilha da imbricação entre cognição e subjetividade, entre linguagem e emoção, o homem evolui no linguajar, conforme Maturana (2001), numa dimensão de busca constante de preservação da vida, do equilíbrio e congruência com o meio que pode desencadear transformações e mudanças estruturais. As mudanças em educação requerem o encontro e a produção com 
artefatos técnicos, modos de comunicar que se produzem quando estamos em experiência inventiva com o jogo de areia.

O jogo de areia no Brasil começou a despertar interesse dos psicólogos, professores e universitários. Porém, sua aplicação é restrita e ainda mais voltada a psicologia clínica. Procuramos com este estudo trazer à discussão uma experiência que efetivamos no campo da educação, em que esta ferramenta se mostra com potência em processos de conhecimentosubjetividade na educação ambiental.

\section{Sobre a ferramenta jogo de areia}

O jogo de areia é constituído por uma caixa que pode ser de madeira, plástico revestido internamente com fundo azul, medindo $72 \times 7,5 \mathrm{~cm}$ e preenchida até a metade com areia seca ou molhada. O professor que o utiliza organiza um armário contendo uma variedade de miniaturas que representam diversas categorias e elementos da natureza: figuras humanas e fantásticas, construções, animais, meios de transporte, acessórios e utensílios para humanos, artigos esportivos, livros, material de higiene pessoal e ambiental, móveis, alimentos e bebidas. Todos estes elementos são trazidos na forma de pequenos objetos que podem compor cenários a serem inventados pelos estudantes.

A aplicação do jogo de areia em seu modelo original inicia quando convidamos o sujeito a montar um cenário dentro da caixa com areia, podendo utilizar-se ou não das miniaturas disponíveis. É essencial que não haja estimulação verbal que anteceda a montagem, nem mesmo ações de interpretação do cenário construído, o que somente podemos realizar após a invenção das cenas pelos estudantes. Estes cuidados são importantes porque permitem a cada estudante uma interação com os objetos na configuração da cena que imagina pertinente à sua experiência.

Dora Kalf indica que a validade do jogo de areia está em proporcionar o que chamou de "espaço livre e protegido." Nesse caso, o paciente para a psicologia clínica tem liberdade para jogar, criar e sentir sem regras fixas. A utilização das miniaturas e da areia permite aos sujeitos a expressão de emoções, ideias, sonhos, inquietudes. A proteção está na caixa, à medida que contém o fluxo expressivo do sujeito; a participação promove acolhimento, confiança, empatia e segurança entre o terapeuta e o paciente. Sustentando a proposta com base Junguiana, podemos referir ao psicanalista quando esclarece que: "Na medida em que conseguia traduzir as emoções em imagens, isto é, ao encontrar as imagens que se ocultava nas emoções, eu readquiria a paz interior (...)" (JUNG, 1975, p.158).

Ao tratarmos da experiência no campo pedagógico, estamos a interagir com os estudantes que trazem seus conceitos, emoções que experimentam ao produzir cenários envolvendo uma temática proposta. 
Solicita-se na hora da socialização da cena, que o estudante narre a história contida no cenário, um diálogo se estabelece. Propomos a indicação de um título, conversamos sobre o cenário e a relação deste com a experiência do estudante que o inventou. Há um registro durante todo o processo, mediante a observação das ações dos participantes. "O poder da imaginação, com sua atividade criativa, liberta o homem da prisão da sua pequenez, do ser 'só isso' e eleva ao estado lúdico" (JUNG apud LEVY, 2007, p.42).

O jogo de areia se coloca como uma tecnologia que permite aos estudantes acederem aos acontecimentos de sua vida em diferentes dimensões, o que trazemos para o campo do fazer pedagógico. A relação que experimentamos com o jogo de areia em uma escola pública de Mossoró considera ainda os estudos de Humberto Maturana que ajudam a entender o conhecer enquanto processo inseparável da constituição de nós mesmos e das realidades em que vivemos.

Nesta contínua reflexão em educação, encontramos a grandiosidade dos estudos de Maturana, cientista que ajuda a explicitar a relação criativa, sistêmica e social do conhecimento, quando destaca: "O amor é a emoção que constitui o domínio de condutas em que se dá a operacionalidade da aceitação do outro como legítimo outro na convivência, e é esse modo de convivência que conotamos quando falamos do social' (MATURANA, 1998, p.23). Seguindo nesta perspectiva, entendemos que a ferramenta do jogo de areia permite aos sujeitos sentirem-se acolhidos em uma proposição de linguajar, na invenção de cenários que se relacionam com suas vidas em um ambiente onde podem dizer de si e do conhecimento.

Neste sentido, a experiência com o jogo de areia permite observar 0 processo transformador dos sujeitos envolvidos, diante da aceitação e disponibilidade para o desenvolvimento da técnica no percurso da história de vida de cada estudante em sua singularidade, o que por vezes está esquecido no campo dos nossos fazeres pedagógicos.

\section{O jogo de areia na Educação Ambiental}

A questão ambiental em nossos dias não está associada apenas ao problema da poluição na terra, mas se volta para o Planeta onde vivemos, onde o aquecimento global, o aumento do buraco na camada de ozônio e o próprio destino do lixo aflige a todos, crescendo como sinal de alerta para as nações cuidarem e reduzirem o consumo de recursos de matérias primas. Para Neto:

[...] a educação ambiental, como resultado da dinâmica do movimento real comum a todas as coisas, pode assumir várias interfaces, configurando-se de acordo com a concepção de mundo que norteia a prática pedagógica do educador ambiental. (NETO, 2010, p.9). 
À medida que a sociedade avança, também cresce o problema do lixo e são poucas as tentativas de sucesso na criação de formas de tratar (NETO, 2010, p.17). Estas inquietações se fazem presentes na trajetória de uma das autoras deste artigo, de modo que organizou e desenvolveu experiência de pesquisa intervenção com jogos de areia em uma escola de Mossoró - a Escola Estadual Dr. Ewerton Dantas Cortez, buscando na pesquisa conhecer as potencialidades da ferramenta jogo de areia em educação ambiental, focalizando em seu estudo, a temática do lixo doméstico. $O$ trabalho envolveu 17 estudantes que acolheram participar da experiência.

O encontro do trabalho pedagógico com a estratégia de oficina em sala de aula se deu na vivência da equipe de apoio pedagógico.

Nessa relação de busca de aprimoramento profissional e estando encarregada na escola de propor experiências em educação ambiental, uma das autoras deste artigo opta em trabalhar com o dispositivo de oficinas, pois percebe nesta ferramenta um potencial para chegarmos à práticas pedagógicas mais dinâmicas em sala de aula, além de configurar em recurso didático onde todos fazem e aprendem juntos. Em oficinas não temos mais um professor que vive a ilusão de que transfere conteúdos e informações para os estudantes, pois é procedimento que envolve o fazer junto, processos de autoria individual e coletiva.

Contextualizar o significado e história de oficina pedagógica implica resgatar o maravilhoso trabalho de Celestin Freinet, pedagogo francês que se preocupava com o processo de escolaridade das crianças oriundas das camadas sociais dos operários e do campesinato francês. Freinet desenvolveu uma prática pedagógica que favorecia a aprendizagem das crianças menos favorecidas economicamente e destinadas no imaginário social ao fracasso escolar. Inventou este educador uma forma de tratar do conhecimento com crianças acompanhada da alegria e dinamismo no ato de aprender. Assim, utilizou-se da oficina pedagógica, alternativa para o processo ensino e aprendizagem. modo envolvente e significativo para o professor e para os estudantes, numa relação de trabalho motivante e participativa.

O dispositivo da oficina educativa vai se configurando como metodologia no exercício da docência, pois é uma "construção coletiva de um saber, de análise da realidade, de confrontação e intercâmbio de experiência" (CANDAU, 1999, p.23).

Oficina como prática pedagógica no Brasil surge na década de 80 , sendo utilizada como uma estratégia de gestão descentralizada pela Secretaria do Estado de São Paulo, visando à capacitação em serviço dos professores da rede de ensino público estadual.

O próprio termo oficina está ligado ao ofício do professor, pois se originou do latim oficina, lugar de trabalho, associado inicialmente ao trabalho manual. Neste sentido, 0 ato de ensinar também é um trabalho que está voltado para o fazer em que o corpo todo está envolvido. 
O dispositivo de oficinas vivenciadas nos anos iniciais enquanto profissional de educação na área do exercício da docência, nos anos 80 e 90, não era bem vista no campo da pedagogia por alguns teóricos, esses, com a concepção behaviorista da transmissão de informações como modelo de conhecimento. No entanto, a minha prática pedagógica já introduzia na escola as oficinas de forma espontânea, com emprego de ferramentas como música popular, dança, atividades recreativas e reflexões com interatividade na sala de aula de modo a torna-la significativa e diferente. Alguns colegas de trabalho rejeitavam e questionavam a prática educativa com a ferramenta da oficina neste período da minha trajetória, outros começavam a incorporar. Até mesmo porque no âmbito da comunidade científica educacional, começam a surgir estudos em diversas áreas que ajudam a comprovar a pertinência do trabalho com oficinas.

As oficinas foram pensadas em educação como proposta de intervenção com o objetivo de favorecer processos de autoria coletiva. Sobre uma perspectiva de tecnologia e interatividade social na forma de oficinas, temos 0 trabalho de Elisângela Zaniol que desenvolveu uma dissertação de mestrado com pesquisa intervenção envolvendo juventude e tecnologias:

(...) Podemos pensar a oficina como uma tecnologia social porque produz um espaço coletivo de trocas, um espaço de atualização de convivências de coordenações de ações, de reflexões, de posições políticas. Constitui uma tecnologia social pela possibilidade de exercício da expressividade e da visibilidade. Elas constroem também uma realidade compartilhada que ganha consistência a partir da interação entre seus participantes (ZANIOL, 2005, p. 40).

Nossa pesquisa se desenvolve como pesquisa intervenção, o que vale dizer que durante $o$ trabalho e também ao final, os resultados que atingimos são compartilhados no transcurso mesmo em que ocorre o fazer das oficinas, para os profissionais da instituição, para as famílias dos jovens e ainda para comunidade interessada como um todo.

$\mathrm{O}$ primeiro contato aconteceu com a finalidade de apresentar $\mathrm{O}$ procedimento das oficinas no jogo de areia com a temática o lixo doméstico, além de constituir em momento de diálogo com os estudantes sobre a história do jogo de areia. Neste mesmo momento, foram apresentados objetos, no caso as miniaturas relacionadas ao tema lixo doméstico e as caixas para o jogo. O segundo encontro já acontece com o fazer em oficinas, onde destacamos a questão: $O$ que é lixo?

Nesse sentido, a questão abordada foi ganhando estilo, qualidade e forma e, depois, foram discutidas algumas dúvidas trazidas pelos alunos: "Eu não estou entendendo nada"! (M) "A minha cadeira quebrada feita de massa de modelagem está no lixo, ou eu posso consertá-la?(L) Já se percebeu muito alegria, quando uma aluna exclamou: "Eu estava louca 
para chegar a hora da oficina! (ME). As perguntas, as ações, reações, emoções, sentimentos demonstraram que os alunos não tinham uma visão clara e conceitos definidos e estruturados quanto ao problema do lixo. Para António Damásio no seu livro: "Em busca de Espinosa: Prazer e dor na ciência dos sentimentos":

Temos emoções primeiro e sentimento depois porque na evolução biológica as emoções vieram primeiras e os sentimentos depois. As emoções foram construídas a partir de reações simples que promovem a sobrevida de um organismo e que foram facilmente adotados pela evolução. (DAMÁSIO, 2004, p.37).

As reações emocionais e os sentimentos dos alunos manifestados na oficina de educação ambiental foram simples, espontâneos e ao mesmo tempo, contagiantes.

Após a distribuição das bandejas de plástico no chão, as crianças sentadas em círculo interagiam com o tema exposto: O que é o lixo? Onde está o lixo? Dialogando, assim, começaram a construção das cenas, quando observamos que se dedicavam mais diretamente à confecção, num rico movimento de gestos que coordenavam entre si na escolha de miniaturas. $O$ emprestar/repassar um objeto ao colega, o dizer sugerindo posição para uma ou outra miniatura no cenário, estas ações coordenadas entre os jovens fazem aprender um elemento que considero essencial na produção do conhecimento relacionado às conexões que estabelecemos entre os elementos na natureza, aqui se tratando da conexão de um para um e de um na relação com o outro, o que Maturana diria como sendo o respeito a si mesmo / a legitimidade de si mesmo e o respeito ao outro / o surgimento do outro como legítimo na convivência (MATURANA, 2001).

Levando em conta a estratégia do jogo de areia, com as atividades de oficinas queremos observar mudanças em condutas, coordenações de ações que, nos seres humanos, ocorrem na linguagem (Figuras 1 e 2). Pensar novamente sobre como compreendem o lixo, como explicam, permite observar em diferentes inscrições - escritas e imagens - mudanças referidas às ideias dos jovens.
(Jovem L) - Parece que todo mundo está com as mesmas coisas
(Jovem LI) - Eu fiz uma casa com o lixo, muito mal organizado. Prejudicando o meio ambiente. E trazendo prejuízo para os vizinhos.
(Jovem W) - Nós temos que reciclar reduzir e reutilizar, (três rrrs), por isso que nós temos que cuidar do nosso lixo, quer dizer do nosso planeta. (Jovem L E) - A gente tem que cuidar da natureza.
(Jovem $E P$ ) - Bom é que eu realmente entenda que as pessoas não jogem muitas coisas no lixo 


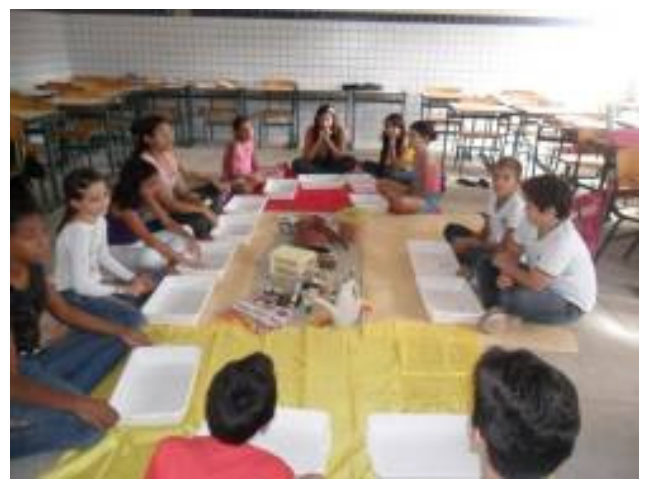

Figura 1: O que é o lixo?

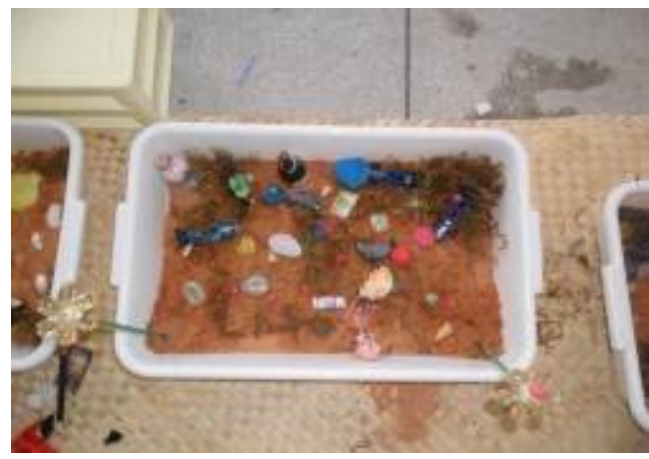

Figura 2: Onde está o lixo?

Observamos que o prazer e a alegria como emoções que sustentavam as ações de invenção de cenários. Citamos a fala de uma aluna: "Eu fiz uma natureza poluída" (E P). Assim, podemos dizer que a memória fica inscrita em um corpo. Em sua narração, a aluna explicou o modo de sentir a realidade e sua percepção, onde há convite para ela mesma rever o seu modo de vida em relação ao lixo doméstico.

A cena demonstra uma desorganização dos recursos materiais produzidos pelo homem no percurso de sua história pessoal e coletiva. Vale indicar a resistência por parte de duas alunas quanto ao contato com areia e a dificuldade na modelagem de alguns objetos que simbolizaram 0 lixo.

Conforme esclarece Ammann (2002), a areia dependendo do seu estado, pode fazer ver alterações entre areia e o vento, movimentos. Enquanto seca é escorregadia; quando é quase líquida ou molhada é leve para o toque, então o seu contato com as mãos é algo macio, carinhoso, gostoso e prazeroso. Nesse caso, possibilita modelagens ampliadas e favorece o aparecimento de formas diferenciadas.

Ao seguir com as oficinas, as jovens se integraram com o elemento areia, entrando no clima de construção dos seus cenários e estabelecendo contato direto com a areia, utilizando as mãos.

A terceira oficina do jogo de areia sobre educação ambiental trouxe a seguinte questão: - Como é feita a separação do lixo na sua casa, rua e bairro? Quando foi lançada a pergunta um aluno questionou: - Como é que a gente vai saber? (L). Neste momento, fazemos o convite para o fazer na oficina, onde ideias, emoções, modos de percepção do tema emergem nas cenas construídas.

A organização da sala de aula se deu para o trabalho em grupo, tendo como materiais cinco bandejas de plásticos, sucatas de copos descartáveis para colar pedaços de folha de casca, tapete com a figura de um urso pando, 
animal ameaçado de extinção, aqui com as cores: azul, amarelo, verde e vermelho.

$\mathrm{Na}$ hora da construção dos cenários (Figuras 3, 4, 5 e 6), muitos movimentos e produções de recursos materiais e perguntas: - Posso construir um carro na areia? (LE) Temos a interação e uma convivência amorosa na construção dos cenários, um clima de harmonia, sensibilidade, criatividade e ludicidade foi fluindo numa dimensão educativa.

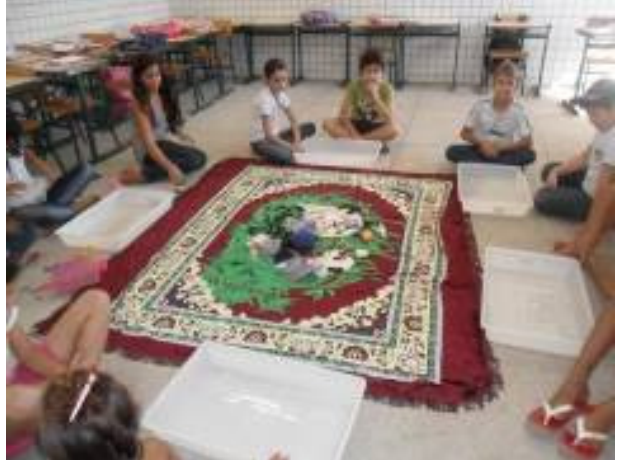

Figura 3: É separado o lixo em minha casa?

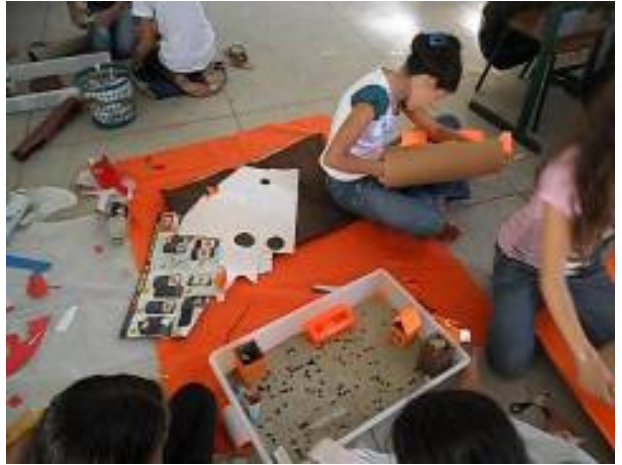

Figura 4: O destino do lixo não reciclável.

Trazer essa alternativa da oficina do jogo de areia a respeito do lixo doméstico para a escola nos anos iniciais constitui um novo meio de responder pelas novas gerações, uma visão e concepção de vida que tomamos como central no percurso como professoras e pesquisadoras do fazer em educação ambiental.

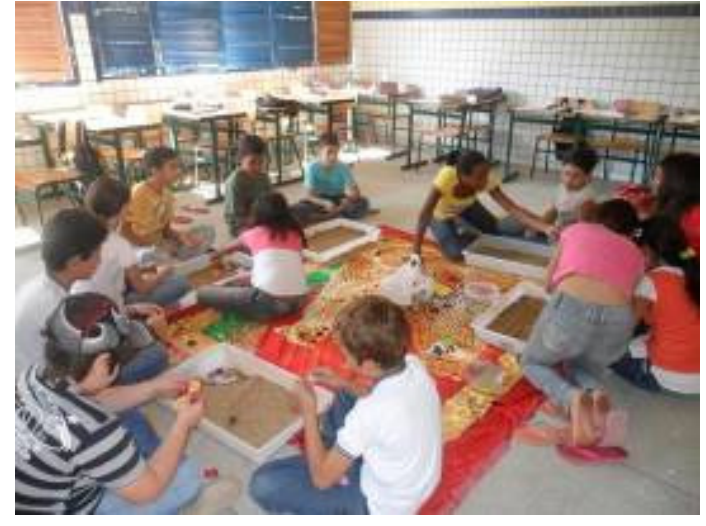

Figura 5: Limpeza do meio ambiente

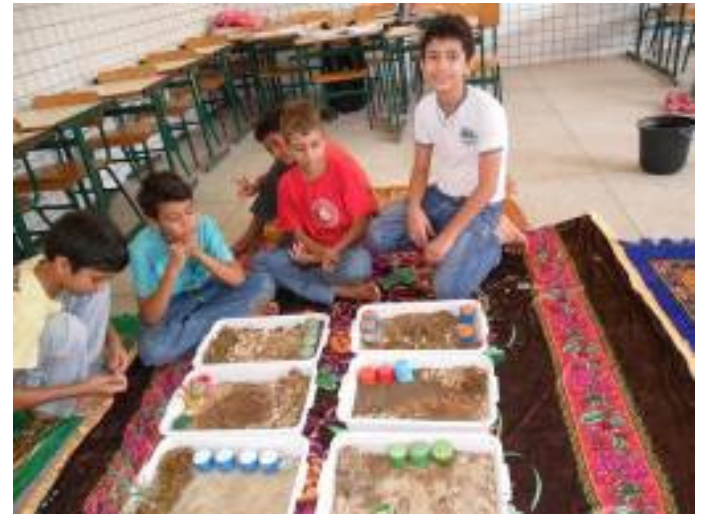

Figura 6: Cuidando da natureza local 
Os olhares fixos dos alunos em suas criações nas oficinas demonstram a capacidade inventiva da realidade, emite vários significados, entre eles: o encantamento com a obra de arte e o desejo de mostrar seus sentimentos. As suas histórias estavam presentes, os cuidados com o lixo se fazem necessários, tanto no que diz respeito ao que nós mesmos fazemos, como em relação aos outros, numa convivência social de incertezas quando pensamos no futuro.

\section{Oficinando com o jogo de areia: deslocamentos e transformações no modo de cuidar do meio ambiente}

È comum encontrar nas escolas orientações escritas afixadas, como: Não jogue o papel no chão! Temos que preservar a natureza! Temos que economizar a água! Conselhos como esses são verbalizados ou mesmo escritos para que os alunos passem a adotar condutas consideradas adequadas para o cuidado com o meio ambiente, entretanto o que vínhamos observando na escola é de que não aconteciam mudanças significativas. Muitas vezes o que temos nas escolas são práticas que se restringem à entrega de manuais de orientação, organização de encontros e palestras direcionadas a informar sobre o necessário cuidado com o meio ambiente.

Já quando convidamos os estudantes a oficinarem, a fazermos junto algo, um cenário com o jogo de areia e as miniaturas, o que temos são efeitos de um processo inventivo. Ideias, perguntas, sentimentos e imagens do que emerge no fazer. Todos estes elementos entram em jogo nas oficinas de jogos de areia. E como já sabemos, nossa memória está inscrita no corpo que se põe a conhecer e viver, um corpo capaz de entendimento.

Nas oficinas houve espaço para que o próprio aluno criasse as cenas, de forma significativa e com implicação. Observamos, assim, que o projeto realizado foge da dimensão comportamental de aconselhamento, das tentativas frustradas em educação ambiental de passar conteúdos, informações, como se fosse possível operar transformações, construir entendimentos, sem que os sujeitos envolvidos possas interagir, fazer junto e refletir. O lixo doméstico em cena permite a construção do conhecimento de modo a entrelaçar o afetivo, o cognitivo, o lúdico em uma experiência de aprendizagem.

A partir das oficinas, o tempo de vida do lixo foi aparecendo e, à medida que apresentava os objetos, os jovens imaginavam onde e como deveriam tomar os cuidados em relação aos tóxicos ou não. Esta ação produz a corresponsabilidade de cada um na relação com o ambiente, na relação consigo e com os outros no ambiente.

Por meio da experiência de reflexão e de investigação sobre as questões ambientais no cotidiano da comunidade e da escola, existe a compreensão de que tanto o professor quanto o sujeito pesquisado, de certo modo, estão em um processo de trocas e aprendizagens constantes (NETO et al., 2010, p.190). 
Os estudantes colocam em cenas uma ponte com água limpa onde aparecem tartarugas nadando. Aqui estão a representar a natureza com ar puro e qualidade de vida. As aranhas estão presentes, um processo de equilíbrio e unidade do homem com o meio ambiente. As pedras são dispostas ficando elevadas, demonstrando que o solo ainda não foi danificado. Observamos nas cenas que o homem está em busca da harmonização de sua relação com a natureza. Vale ressaltar uma reflexão necessária sobre como compreendemos a educação ambiental. Estamos de acordo com Barcelos, quando esclarece que: "... ninguém é contra a educação ambiental - já que a educação ambiental é importante e também considerada administrativamente como prioridade pelas instituições oficiais de gestão e de planejamento que tratam da organização escolar" (BARCELOS, 2008, p.82). No entanto, muito dos planejamentos escolares fogem da realidade local, neste caso a escola que, em muitas situações vividas em relação à educação ambiental, não incorpora no seu Projeto Político Pedagógico a prioridade a esta questão da sustentação do viver.

A defesa de alguns sujeitos e cidadãos consiste em buscar contribuições para que as ações humanas diminuam em seu cotidiano a agressão ao meio ambiente. A escola é espaço vivo e fértil para conservação, preservação e para um exercício transformador quanto à preservação da vida humana e da vida dos demais seres vivos na natureza. António Damásio nos ajuda nesta reflexão, quando coloca:

Quando enfrentamos cada novo momento da nossa vida, como seres conscientes, influenciamos esse momento com as circunstâncias das alegrias e tristezas passadas, bem como com as circunstâncias imaginárias do nosso futuro antevisto, essas circunstâncias futuras que, presumivelmente, nos trarão mais alegrias e mais tristezas (DAMÁSIO, 2004, p.283).

As cenas dão visibilidade ainda à organização do lixo, ao modo com os estudantes vivenciam o tratamento do lixo em suas residências ou mesmo nas comunidades onde moram.

Os recursos materiais utilizados foram depósitos de plástico de condimentos de cozinha colorido, como representante para construir simbolicamente coletores para seleção do lixo, proposta da reciclagem e reutilização do lixo.

Os olhares fixos dos alunos em suas criações demonstram a capacidade inventiva da realidade, o encantamento com a cena produzida e o desejo de mostrar seus sentimentos e ideias. As suas histórias estavam presentes, os cuidados com o lixo se fazem necessários, tanto no que diz respeito ao que nós mesmos fazemos, como em relação aos outros, numa convivência social de incertezas quando pensamos no futuro. 
A missão da escola mudou que em vez de atender a uma massa amorfa de alunos, despersonalizados, é preciso focalizar o indivíduo, aquele sujeito original, singular, diferente e único; dotado de inteligências múltiplas, que possui diferentes estilos de aprendizagem e, consequentemente, diferentes habilidades para resolver problemas" (MORAES, 2002, p.15).

Refletir sobre esta nova possibilidade no processo de ensinar e aprender é um modo diferente de ver e entender os nossos jovens de hoje.

Aqui os alunos trazem os conceitos de seleção de lixo numa visão bem próxima de sua realidade, quando dizem: "Na minha casa nos reciclamos o lixo e colocamos na frente da nossa casa para que o carro da coleta seletiva passe e leve para a reciclagem, ao levar transformam lixos em objetos para as pessoas usarem novamente" (ME).

Percebe-se que quando lixo é reciclado para outras pessoas, o aluno não poderá usar o recurso utilizado. O sujeito precisa entender que o mesmo lixo faz parte do processo histórico, esse modificado ou não.

Outra fala e escrita: "lixo é sujo, mais pode ser reutilizado." O conceito reutilizado foi introduzido pela professora quando inicio o projeto de ensino, com o tema: A simulação do lixão, conteúdo também da disciplina de Ciências, todo esse processo provocou uma verdadeira festa de alegria nos alunos, descobriram valores adormecidos e esquecidos.

O jogo de areia aflora lado emocional dos sujeitos envolvidos com a técnica, além de humanizar o homem, esse em processo de desumanização. Chega a uma consciência de vida, onde, o mundo que eu vivo, também têm outros que aprendem juntamente comigo, e eu aprendo com eles.

Para Maturana: o amor é a emoção que constitui as ações de aceitar o outro como um legítimo outro na convivência. Portanto, amar é abrir um espaço de interações recorrentes com o outro, no qual sua presença é legítima, sem exigências... O amor é um fenômeno biológico tão básico e cotidiano no humano, que frequentemente o negamos culturalmente criando limites na legitimidade da convivência, em função de outras emoções (MATURANA, 2010).

\section{Considerações finais}

O jogo de areia na educação favorece uma experiência em que o processo de aprendizagem se mostra atravessado por emoções, desejos, projetos de vida, alegrias, sofrimentos. Educação é um campo que opera com aprendizagem de conteúdos, mas estes ganham sentido quando se conectam com um corpo que se movimenta mediante múltiplas formas de conhecer na linguagem. Educar é percurso que envolve a imaginação, a sensibilidade, as emoções e a afetividade de uma forma mais profunda nos sujeitos estudantes, professores. E o jogo de areia preserva este espaço em que o aprender é 
processo do fazer, do sentir, da reflexão e da capacidade inventiva dos seres humanos.

A dinâmica das oficinas do jogo de areia em relação ao lixo doméstico, além de despertar o lúdico e a sensibilidade de cada aluno, numa dimensão educativa e social, envolveu as emoções e sentimentos dos jovens alunos, configurando a realidade, na perspectiva do saber pensar, sentir e agir no meio ambiente local com sustentável.

Nesta fertilização de interessados e envolvidos na pesquisa, o resultado ultrapassou ao limite da sala de aula, atingindo ao corpo docente, crescendo assim, a intenção e atenção em mexer as sensações, criações e desejos de aprender brincando, numa linguagem e prazerosa e de alegria.

Do ponto de vista de Moraes: "A educação compreendida como sistema aberto implica a existência de processos transformadores que decorrem da experiência, algo inerente a cada sujeito e que depende da ação, da interação e da transação entre sujeito e objeto, indivíduo e meio" (MORAES, 1997, p.99).

Nesta perspectiva do fazer educativo que aponta Maria Cândida Moraes, as mudanças urgem em relação ao meio ambiente e ao fazer educativo.

As transformações dos conceitos dos alunos relacionados ao lixo doméstico, foram se construindo no percurso da experiência, percebidos na convivência destes com a linguagem ecológica sobre a qualidade de vida, de modo a construírem um novo olhar, uma nova forma de perceber o ambiente que o circunda, escola e outros locais de convivência.

$\mathrm{Na}$ experiência, houve um encontro das histórias de vida dos alunos, com as questões levantadas sobre o lixo doméstico que foi associado ao exercício da cidadania, e a riqueza das ideias na realidade social e histórica. A cada anotação no diário de campo, se vislumbrava uma compreensão diferente sobre o lixo. As modificações de conceitos sobre o lixo doméstico, que antes era visto pelos alunos como algo distante de si, foi ampliado com outros conceitos: poluição, destruição, reaproveitamento, reciclagem, reutilização, dentre outros.

Para ampliação dos conhecimentos a respeito da educação ambiental: lixo doméstico, foi valioso e pertinente o uso da tecnologia presente na sala de informática da escola, onde construímos um blog para socialização das temáticas.

Atualmente as reflexões da ciência nos situam na relação direta com novos paradigmas que permitem perceber que somos parte de um mesmo mundo. Os pensamentos sistêmicos e ecológicos, que juntos confluem no que poderemos chamar de pensamento ecossistêmico influenciam, não apenas a visão que temos do universo e de como ele opera, mas também sobre como se constrói o conhecimento, como os indivíduos operam mentalmente, vivem/convivem socialmente (Cf: MORAES, 2004, p.146). Este novo entendimento sobre como conhecemos-vivemos requer 0 encontro de 
estudantes e professores com artefatos técnicos que potencializam o linguajar, a experiência do conhecer, do conhecer-se e da invenção da própria vida.

Neste sentido, a experiência com o jogo de areia no exercício da docência desenvolve melhor as potencialidades encontradas e muitas vezes adormecidas nos percursos escolares de estudantes e professores. É essencial aprendermos a sentir o valor da educação escolar, numa amorosidade dos seres humanos no modo de conviver na escola. Assim, estaremos buscando realizar uma educação que conspira e se alia ao processo de realização integral do que pode vir a ser o humano, cada vez mais amoroso e capaz de cuidar, de aprender, de se fazer feliz com os outros.

\section{Referências}

AMMANN, R. A terapia do jogo de areia. São Paulo: Editora Paulus, 2002.

ARIĖS, P. História social da criança e da família. Rio: Zahar.1978.

BYINGTON, Amadeu Botelho. A construção amorosa do saber: fundamentos e finalidade da pedagogia simbólica junguiana. Editora ReligarE, 1993.

CAPRA, F. O Tao da física: uma exploração do paralelo entre a física moderna e o misticismo oriental. Lisboa: Editorial Presença, 1989.

DAMÁSIO, A. Em busca de Espinosa: prazer e dor na ciência dos sentimentos. São Paulo: Companhia das Letras, 2004.

FRANCO, A.; PINTO, E.B. O mágico jogo de areia em pesquisa. Dissertação de mestrado, Curso de Pós-Graduação em Psicologia Clínica do IPUSP, 2007.

HUIZINGA, J. Homo ludens: o jogo como elemento da cultura. Editora Perspectiva. 1938.

JUNG, C.G. Memórias, sonhos, reflexões. Rio de Janeiro: Nova Fronteira, 2006.

LEVY, E.G. Tornar-se quem se é: a constelação do self no jogo de areia. Porto Alegre: Armazém Digital, 2011.

MACHADO, M.M. et al. O jogo de areia: um estudo sobre indicadores de resistência ao instrumento. Boletim de Iniciação Científica em Psicologia. 2001. MATURANA, H.R.; VARELA, F.J. A árvore do conhecimento: as bases biológicas da compreensão humana. São Paulo: Palas Athena, 2001.

MATURANA, H.R.; VERDEN-ZOLLER, G. Amar e brincar: fundamentos esquecidos do humano. São Paulo, 2004.

MATURANA, H.R. Emoções e linguagem na educação e na política. Belo Horizonte: UFMG, 1998.

MORAES, M.C. O paradigma educacional emergente. Campinas: Papirus, 1997. MORAES, M.C. Pensamento Eco-Sistêmico: educação, aprendizagem e cidadania no século XX. Petrólis, RJ: Vozes, 2004.

SCOZ, B.J.L. O jogo de areia (Sandplay), subjetividade e produção de sentidos. Março/2008.

WINICOTT, D. O brincar e a realidade. Trad. de José Octávio de Aguiar Abreu e Vanede Nobre. Rio de Janeiro, Imago, 1975. W10 - Playing and Reality. London, Tavistock, 1971. 